\title{
Cuidando da Hipertensão no Consultório
}

\author{
Treating Hypertension in the Doctor's Office
}

Paulo César B. Veiga Jardim

Faculdade de Medicina da Universidade Federal de Goiás - Goiânia, GO

Receber no consultório um paciente portador de hipertensão arterial e fazer ou confirmar seu diagnóstico é estabelecer um convívio que se espera duradouro, pois isso vai significar um bom cuidado e uma boa relação médico-paciente ${ }^{1,2}$.

A cumplicidade do médico com seu paciente é o primeiro passo a ser dado, e é absolutamente imprescindível para o sucesso de qualquer tratamento. Essa parceria deve se concretizar desde o primeiro momento, e cabe a nós, sabedores dessa necessidade, caminharmos em direção a este objetivo ${ }^{1,2}$.

Saber ouvir e ouvir muito. Interessar-nos por cada detalhe da vida desse novo parceiro. Compreender o seu dia a dia, conhecer seus hábitos, inteirar-nos dos seus anseios e angústias, valorizar suas informações ${ }^{1,2}$.

A aceitação de uma "doença" não é automática. Isso se torna mais complicado quando a alteração surge em fase precoce da vida; na maioria das vezes não causa sintomas e seu tratamento vai obrigar a modificações no cotidiano da pessoa.

O segundo passo é a informação. Devemos ser claros, simples e repetitivos, tendo em mente que só ouvimos o que nos interessa. É, portanto, necessário repetir e repetir, de maneiras diferentes, sempre e mais. Um paciente bem informado tem melhores condições de assumir o tratamento. A informação é nossa total responsabilidade, deve ser verbal, escrita e visual ${ }^{1-3}$. Nunca deve ter fim.

O terceiro passo, tão importante quanto os já descritos, é a disponibilidade. Nada melhor que o contato fácil, a possibilidade do esclarecimento de uma dúvida, o suporte num momento de insegurança. Um telefone para apoio, um endereço de referência sempre acessível e, nos últimos tempos, um e-mail ${ }^{1-6}$.

É muito rara a hipertensão isolada, quase sempre há alguma associação de fatores de risco. Enquanto investigamos a enfermidade, já devemos iniciar as negociações para a adoção de hábitos de vida saudáveis ${ }^{4-6}$. Afinal, a vida é feita de trocas.

Seja incisivo, mas não inflexível, negocie sempre, saiba avançar e retroceder quando necessário. Estaremos sempre interferindo em hábitos que fazem parte da cultura da pessoa, sua modificação demanda tempo. Tempo, informação e negociação.

Cada vez mais temos a convicção de que não basta tratar os números; hipertensão é bem mais que isso. 0 benefício será tão maior quanto mais abrangentes formos em nossa ação. Cada fator de risco associado (tabagismo, dislipidemia, obesidade, sedentarismo, estresse, álcool excessivo e diabetes) deve receber a mesma atenção.

O tratamento não-medicamentoso é indicado para todos. Quando não for suficiente para o controle da pressão, tornará menor a quantidade da medicação necessária e fará que os fármacos tenham sua ação mais efetiva ${ }^{4-6}$.

Devemos dar aos indivíduos informações detalhadas sobre cada um dos riscos presentes, sua importância e como fazer para modificá-los.

O método mais efetivo do abandono do tabagismo é o aconselhamento médico, nunca nos esqueçamos desse fato ${ }^{4-6}$.

A orientação sobre uma alimentação com baixo teor de sódio deve ser simples e clara. Da mesma maneira, ao indicar uma dieta hipolipídica, hipocalórica ou hipouricêmica, temos que ser didáticos e preocupar-nos com detalhes (tipos de alimentos, medidas caseiras, qualidade, horários) ${ }^{4-13}$. E repetir e reforçar as informações a cada retorno.

As metas de Índice de Massa Corpórea saudável devem ser discutidas. A diminuição de $10 \%$ no peso por etapas, a cada seis a dez meses, torna os resultados mais fáceis de serem alcançados e as frustrações, menos evidentes. Atingir essa meta torna o benefício bastante significativo ${ }^{4-7,9,10}$.

A orientação sobre atividade física deve também ocupar parte de nosso tempo. Reforçar que todo tipo de movimentação é bem-vindo e indicar a busca do exercício mais prazeroso. A caminhada, em princípio, não tem contraindicação e deve ser a atividade mínima recomendada ${ }^{4-6}$.

As informações sobre as bebidas alcoólicas não devem ser desprezadas; quantidade, qualidade, periodicidade precisam ser detalhadamente descritas. Assim fica mais fácil a compreensão e a aceitação ${ }^{12}$.

$\mathrm{O}$ diabetes necessita de controle sem trégua. Este controle deve ser rigoroso e contínuo. Quanto melhor,

Correspondência: Paulo César B. Veiga Jardim • Rua 115-F, n.135 - Setor Sul - 74085-300 - Goiânia, GO E-mail: fvjardim@terra.com.br Recebido em 02/05/05 - Aceito em 04/05/05 
maior o benefício. Novamente a informação é elementochave para o sucesso ${ }^{4-7,10}$

O uso de fármacos anti-hipertensivos, quando necessários (e cada vez são mais necessários), também deve ser bastante discutido. Motivos para seu uso, tempo, tipo de medicamento, número de tomadas, horários, necessidade de associação, possibilidade de efeitos adversos e assim por diante. Temos na atualidade uma boa variedade de drogas com muito boa eficácia e efetividade ${ }^{4-6,14,15}$. São praticamente isentas de efeitos colaterais e quando usadas isoladas ou em associação, atendem plenamente às necessidades de controle da pressão e diminuem a morbidade e mortalidade. É preciso que sejam ingeridas regularmente, de acordo com a recomendação médica. Aqui novamente a informação precisa é crucial e o esclarecimento de dúvidas, obrigatório. Neste particular, ainda persistem crenças e histórias sobre os medicamentos e devemos ser ativos no rompimento dessas barreiras.

A continuidade do tratamento é outro ponto que sempre suscita dúvidas e temos de ser incansáveis ao enfatizar e esclarecer esse tópico.

Fornecer prescrições legíveis e claras. O que parece estar escrito de maneira inteligível para nós nem sempre o é para o paciente. A preocupação com uma linguagem simples, a anotação de horários, a referência a momentos marcantes (períodos do dia, refeições, sono etc), e novamente a necessidade do uso contínuo devem estar detalhados na nossa receita 2,3,5.

Finalmente, devem ser estabelecidos retornos de maneira objetiva. A liberalidade na marcação das consultas é totalmente prejudicial. Da mesma forma, os retornos em intervalos muito prolongados contribuem para uma piora na adesão. Cada volta deve ocorrer em período definido (nunca maior que seis meses), preferencialmente com a marcação de um dia exato e um contato telefônico para a confirmação $0^{3,4}$.

Os faltosos devem ser alvo de busca ativa, por telefone, telegrama ou carta breve. Esse expediente tem grande eficácia e reforça a relação de parceria entre o paciente e o médico responsável ${ }^{3-5}$.

Procuramos expressar assim nosso ponto de vista, trazendo aos colegas um pouco de nossa experiência e mostrando a estratégia que utilizamos tanto no consultório privado quanto nos consultórios da Liga de Hipertensão, nesse último caso facilitado pela presença de uma equipe multiprofissional.

O uso desses métodos tem propiciado uma melhor adesão do paciente ao tratamento, permitindo melhor controle de sua pressão arterial e dos fatores de risco associados.

\section{REFERÊNCIAS}

1. Rodrigues Branco RFG Y. A Relação com o Paciente. Teoria, Ensino e Prática. Rio de Janeiro: Guanabara Koogan, 2003, 324p.

2. Nobre F, Pierin AMG, Mion Jr D. Adesão ao Tratamento. O Grande Desafio da Hipertensão. São Paulo: Lemos Editorial, 2001: 118p.

3. Jardim PCBV, Sousa, ALL, Monego ET. Atendimento multiprofissional ao paciente hipertenso. Medicina Ribeirão Preto, 1996; 29: 232-8.

4. IV Diretrizes Brasileiras de Hipertensão Arterial. Arq Bras Cardiol 2004;82(supl. IV): 1-40.

5. Chobanian AV, Bakris GL, Black HR et al. National High Blood Pressure Education Program Coordinating Committee. The Seventh Report of the Joint National Committee on Prevention, Detection, Evaluation and Treatment of High Blood Pressure. Hypertension 2003; 42: 1206-52.

6. 2003 European Society of Hypertension - European Society of Cardiology guidelines for the management of arterial hypertension. J Hypertens 2003; 21: 1011-23.

7. Kraus RM, Eckel RH, Howard B. AHA Dietary Guideline. Circulation 2000; 102: 2284-99.

8. Nakasato M. Sal e hipertensão arterial. Rev Bras Hipertens 2004; 11: 95-7.
9. Nonino-Borges CB, dos Santos JE. Terapia nutricional nas alterações metabólicas associadas à hipertensão arterial (diabete melito, dislipidemias, hiperuricemia). Rev Bras Hipertens 2004; 11: 98-101.

10. Monego ET, Maggi C. Gastronomia na promoção da saúde dos pacientes hipertensos. Rev Bras Hipertens 2004; 11: 105-8.

11. Jardim PCBV, Monego ET, Reis MAC. Potássio, cálcio, magnésio e hipertensão arterial. Rev Bras Hipertens 2004; 11: 109-11.

12. Souza WKSB, Amaral GF. Álcool, hipertensão arterial e doença cardiovascular. Rev Bras Hipertens 2004; 11: 112-14.

13. Grundy SM, Hansen B, Smith Jr. S et al. Clinical Management of Metabolic Syndrome. Circulation 2004; 109: 551-6.

14. Williams B. Recent Hypertension Trials. Implications and Controversies. J Am Coll Cardiol 2005;45:813-27.

15. Blood Pressure Lowering Treatment Trialists Collaboration. Effects of different blood -pressure-lowering regimes on major cardiovascular events: results of prospectively-designed overviews of randomized trials. Lancet 2003; 362: 1527-45. 